\title{
Borderline left ventricle: Trying to see the forest for the trees
}

\author{
Emile Bacha, MD
}

From the Section of Congenital and Pediatric Cardiac Surgery, Division of Cardiac, Thoracic and Vascular Surgery, Morgan Stanley Children's Hospital, NewYork-Presbyterian, Columbia University, New York, NY. Disclosures: Author has nothing to disclose with regard to commercial support.

Received for publication March 17, 2017; accepted for publication March 21, 2017; available ahead of print April $20,2017$.

Address for reprints: Emile Bacha, MD, Section of Congenital and Pediatric Cardiac Surgery, Division of Cardiac, Thoracic and Vascular Surgery, Morgan Stanley Children's Hospital, NewYork-Presbyterian, Columbia University, 3959 Broadway, New York, NY 10032 (E-mail: eb2709@cumc.columbia.edu).

J Thorac Cardiovasc Surg 2017;154:570-1

$0022-5223 / \$ 36.00$

Copyright $(\underset{0}{ } 2017$ by The American Association for Thoracic Surgery

http://dx.doi.org/10.1016/j.jtcvs.2017.03.093

The question "Is a patient better off with single ventricle palliation (SVP) versus a complex biventricular (BiV) repair?" is frequently asked during many catheter conferences across the world. It is a vexing question, for there is no good solid scientific evidence on which to base any answer. No group is better positioned to shed light on the issue than the Boston group. ${ }^{1}$ This article focuses on patients who have been initially managed with SVP and are, after staged left ventricular recruitment (SLVR) procedures (a combination of atrial septal defect restriction, aortic or mitral valve replacement or repair, and endocardial fibroelastosis resection), considered for takedown and $\mathrm{BiV}$ repair. This study is commendable for 2 reasons: (1) It focuses strictly on the 2 main diagnostic groups only (without contamination by other groups), and (2) it attempts to add a physiologic variable to our decision-making armamentarium. Thus far, imaging data from echocardiography (size and function) and magnetic resonance (size, function, and flow) primarily have been used..$^{2-4}$

We learn several things:

1. The predictive preoperative physiologic marker was a left ventricular end-diastolic pressure (LVEDP) of $13 \mathrm{~mm} \mathrm{Hg}$ or more. Of note, the preoperative left atrial pressure was not, presumably because of the often present mitral valve anomalies.

2. The primary end point (consisting of death, heart transplant, or BiV takedown) was reached by $22 \%$ (11/ 51) of patients. Ten of the 11 patients had hypoplastic left heart syndrome (HLHS). Despite falling out of the multivariable analysis in the end, this is powerful evidence, statistics or not, that borderline HLHS is a risk factor for poor outcomes. Also, one third of patients with borderline HLHS experienced a primary end point versus only 1 of 18 patients with unbalanced atrioventricular canal.

3. Patients with SLVR and BiV repair in whom elevated right ventricular pressure greater than three quarters of the systolic blood pressure develops will essentially reach one of the primary end points.

4. Surgical reintervention after $\mathrm{BiV}$ conversion was required in approximately half $(49 \%)$ of the patients.

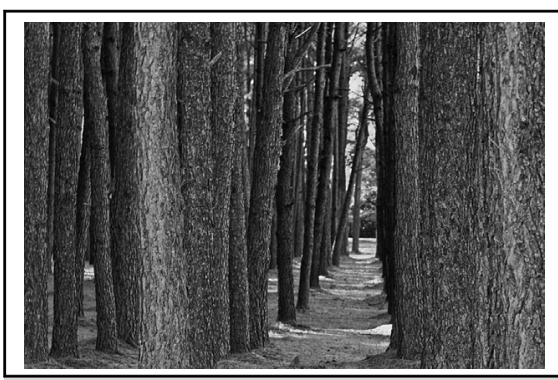

Forest for the trees. From Wikimedia Commons, the free media repository.

Central Message

New pathophysiologic knowledge on SLVR and $\mathrm{BiV}$ repair in a borderline left heart is gained from this study, but observed survival makes the strategy less certain.

See Article page 572

5. Finally, and most important, the survival statistics exposed in this study are sobering: a transplant-free survival of $80 \%$ at 3 years for the entire cohort $(85 \%$ for the group with LVEDP $<13$ and $60 \%$ for the other group). This is in a setting where patients were preselected for $\mathrm{BiV}$ conversion only if they demonstrated growth of left heart structures! In addition, because the survival curve starts at the time of BiV surgery, these patients already have incurred a risk during their previous surgeries, and their survival starts to look similar to that of 1-year survivors of HLHS palliation: $90 \%$ to $95 \%$ survival at 3 years. ${ }^{5}$ Granted, the principal aim of the study was to "investigate pre- and postoperative hemodynamics and outcomes in BiV following SVP." "This aim has been achieved. However, the authors also aim to "describe a single institution experience with BiV conversion," and that side of the story, I would argue, has not been sufficiently debated.

The patients who are candidates for SLVR and BiV repair typically can be divided into 2 groups: one group that is not tolerating SVP (eg, patients with protein-losing enteropathy) and one group that is doing well clinically but has left-sided heart structures that are deemed possible to rehabilitate. Given the survival data and the high number of total surgeries per patient required, it would be crucial to understand what the preoperative status was. If these were mostly elective surgeries and decision-making was made on the basis of favorable structural left heart components 
in an otherwise well patient with single-ventricle (SV) physiology, one should pause and contemplate whether this is the correct approach. In the article, the authors mention only that "the majority of patients had risk-factors for SV palliation," " without giving any more details. Indeed, if one is to try to make a grand philosophical judgment on the merits of the SLVR/BiV approach, what is missing is data on the clinical indications for going down this route as opposed to staying on SV palliation.

Many of the findings of this article are meaningful in a practical way. ${ }^{1}$ The next time I see a patient with borderline HLHS and elevated LVEDP, I might be more circumspect in recommending BiV conversion. Conversely, I might be more aggressive with a patient with unbalanced atrioventricular canal. The increase in right ventricular pressure also is concerning. The authors are recommending regular (ie, annual) [sic] catheterizations, a not insignificant burden and a sign that the specter of pulmonary hypertension can never be ignored in these patients. ${ }^{1}$ At this junction, for the patients with borderline HLHS and elevated LVEDP not tolerating SV physiology, we might have to change our thinking, such as recommending heart transplantation or assist devices. There is no doubt that the cumulative team experience in Boston has helped many patients reach meaningful survival with BiV physiology. We are hopeful that these new data will allow, at least for practitioners who like me are believers in this approach, for better triage of the patients who will be the real beneficiaries.

\section{References}

1. Herrin MA, Zurakowski D, Baird CW, Banka P, Esch JJ, del Nido PJ, Emani SM Hemodynamic parameters predict adverse outcomes following biventricular conversion with single ventricle palliation takedown. J Thorac Cardiovasc Surg. 2017; $154: 572-82$.

2. Emani SM, McElhinney DB, Tworetzky W, Myers PO, Schroeder B, Zurakowski D, et al. Staged left ventricular recruitment after single-ventricle palliation in patients with borderline left heart hypoplasia. J Am Coll Cardiol. 2012;60:1966-74.

3. Mery CM, Nieto RM, De León LE, Morris SA, Zhang W, Colquitt JL, et al. The role of echocardiography and intracardiac exploration in the evaluation of candidacy for biventricular repair in patients with borderline left heart structures. Ann Thorac Surg. 2017;103:853-61.

4. Cavigelli-Brunner A, Bauersfeld U, Prêtare R, Kretschmar O, Oxenius A, Valsangiacomo Buechel ER. Outcome of biventricular repair in infants with multiple left heart obstructive lesions. Pediatr Cardiol. 2012;33: 506-12.

5. Newburger JW, Sleeper LA, Frommelt PC, Pearson GD, Mahle WT, Chen S, et al Transplantation-free survival and interventions at 3 years in the single ventricle reconstruction trial. Circulation. 2014;129:2013-20. 